\title{
Pathways to HIV risk and vulnerability among lesbian, gay, bisexual, and transgendered methamphetamine users: a multi-cohort gender-based analysis
}

Brandon DL Marshall ${ }^{1,2}$, Evan Wood ${ }^{1,3}$, Jean A Shoveller ${ }^{2}$, Thomas L Patterson ${ }^{4}$, Julio SG Montaner ${ }^{1,3}$, Thomas Kerr ${ }^{1,3^{*}}$

\begin{abstract}
Background: Methamphetamine (MA) use continues to be a major public health concern in many urban settings. We sought to assess potential relationships between MA use and individual, social, and structural HIV vulnerabilities among sexual minority (lesbian, gay, bisexual or transgendered) drug users.

Methods: Beginning in 2005 and ending in 2008, 2109 drug users were enroled into one of three cohort studies in Vancouver, Canada. We analysed longitudinal data from all self-identified sexual minority participants $(n=248)$. Logistic regression using generalized estimating equations (GEE) was used to examine the independent correlates of MA use over time. All analyses were stratified by biological sex at birth.
\end{abstract}

Results: At baseline, 104 (7.5\%) males and 144 (20.4\%) females reported sexual minority status, among whom 64 $(62.1 \%)$ and $58(40.3 \%)$ reported MA use in the past six months, respectively. Compared to heterosexual participants, sexual minority males (odds ratio $[\mathrm{OR}]=3.74, p<0.001)$ and females $(\mathrm{OR}=1.80, p=0.003$ ) were more likely to report recent MA use. In multivariate analysis, MA use among sexual minority males was associated with younger age (adjusted odds ratio $[\mathrm{AOR}]=0.93$ per year older, $p=0.011)$, Aboriginal ancestry $(\mathrm{AOR}=2.59, p$ $=0.019$ ), injection drug use ( $A O R=3.98, p<0.001$ ), having a legal order or area restriction (i.e., "no-go zone") impact access to services or influence where drugs are used or purchased ( $A O R=4.18, p=0.008$ ), unprotected intercourse ( $A O R=1.62, p=0.048)$, and increased depressive symptoms ( $A O R=1.67, p=0.044)$. Among females, MA use was associated with injection drug use ( $A O R=2.49, p=0.002)$, Downtown South residency (i.e., an area known for drug use) ( $A O R=1.60, p=0.047)$, and unprotected intercourse with sex trade clients ( $A O R=2.62$, $p=0.027)$.

Conclusions: Methamphetamine use was more prevalent among sexual minority males and females and was associated with different sets of HIV risks and vulnerabilities. Our findings suggest that interventions addressing MA-related harms may need to be informed by more nuanced understandings of the intersection between drug use patterns, social and structural HIV vulnerabilities, and gender/sexual identities. In particular, MA-focused prevention and treatment programs tailored to disenfranchised male and female sexual minority youth are recommended.

\footnotetext{
* Correspondence: uhritk@cfenet.ubc.ca

${ }^{1}$ British Columbia Centre for Excellence in HIV/AIDS, St. Paul's Hospital, 608-

1081 Burrard Street, Vancouver, BC, V6Z 1Y6, Canada

Full list of author information is available at the end of the article
} 


\section{Background}

Like many other marginalised groups, lesbian, gay, bisexual, and transgendered (LGBT) populations experience a range of health inequities and vulnerabilities compared to the general population [1]. In addition to the multiple health conditions that disproportionately affect LGBT populations, sexual minorities also experience significant barriers to accessing appropriate care and prevention services [2,3]. Due in part to the historical invisibility of LGBT persons and a reluctance among some communities to consider sexual minorities as a "legitimate" marginalised group, this population continues to be underrepresented in public health research and practice [4].

A number of studies have demonstrated a high prevalence of substance use and dependence among sexual minority groups $[5,6]$. For example, methamphetamine (MA) use has been well studied among gay, bisexual, and other men who have sex with men (MSM), particularly in relation to increased sexual risk behaviour and HIV transmission [7-9]. Although much less research has been conducted among sexual minority women, several cross sectional studies have demonstrated that lesbian and bisexual-identified females report significantly higher rates of MA use $[10,11]$. MA use among women who inject drugs (IDU) has also been associated with sexual- and injection-related HIV risk behaviour [12]. These studies and other research imply important gender differences in the typologies of and adverse health outcomes associated with MA use [13]; therefore, gender-based analyses involving sexual minority populations are needed to better inform effective public health approaches and practice.

Although the individual and psychosocial factors that drive HIV risk within the context of MA use are relatively well understood [14-16], research has only begun to elucidate how environmental and structural determinants link MA use with increased HIV vulnerability [17]. In order to most effectively reduce MA-related exposure to HIV risks, several authors have called for the investigation of personal, social, environmental, and structural correlates of MA use and harms $[17,18]$. The "risk environment" framework, which posits that factors exogenous to the individual intersect to (re)-produce HIV risk and other drug-related harms [19], provides one such conceptual model to guide investigation of the associations between MA use and HIV vulnerabilities operating at various levels of influence.

Using data collected from three large ongoing prospective cohort studies of drug users in Vancouver, Canada, we sought to determine the prevalence of MA use among sexual minority males and females. Furthermore, relying on a risk environment approach, we assessed the relationships between MA use and a range of individual, social, and structural HIV-related vulnerabilities with the aim of indentifying through which pathways MA use may exacerbate exposure to HIV risk.

\section{Methods}

\section{Study Design}

The At Risk Youth Study (ARYS), Vancouver Injection Drug Users Study (VIDUS) and AIDS Care Cohort to Evaluate Access to Survival Services (ACCESS) are open prospective cohorts of drug users in Vancouver, Canada. These studies comprise a larger program of research focused on the study of the initiation and natural history of injection drug use, and are administered by one research centre (i.e., the British Columbia Centre for Excellence in HIV/AIDS). The risk environment framework is utilized as the theoretical foundation from which to examine how a variety of factors within social, physical, and political space interact to (re)-produce HIV and drug-related harm [19]. Recruitment procedures for the three studies are similar, with the primary modes of enrolment being self-referral, word of mouth, and street outreach. Participants of all studies must have resided in the greater Vancouver region and provided informed consent to be eligible. Each study also had specific eligibility criteria that are detailed briefly here. ARYS consists of drug-using street-involved youth; thus, eligibility criteria included being between the age of 14 and 26 and the use of illicit drugs other than or in addition to marijuana in the past 30 days. VIDUS is a study of HIV-negative IDU in which all participants must have injected an illicit drug in the past 6 months to be eligible for inclusion. ACCESS is a cohort of HIV-positive individuals, who, similar to those in ARYS, must have recently used an illicit drug other than or in addition to marijuana. Detailed sampling and recruitment procedures for these three cohorts have been described elsewhere [20-22]. In this analysis, we combined data from all three studies to achieve a sample size with sufficient power to examine MA use among the sub-sample of participants who identified as a sexual minority. While combining data from studies with different inclusion criteria may present some challenges, we note that all studies rely on harmonized recruitment and data collection tools. Furthermore, combining the datasets permitted an examination of MA use patterns across a diverse spectrum of drug users (e.g., street-involved youth, older IDU) in our setting.

At baseline and semi-annually, participants completed a lengthy interviewer-administered questionnaire. Sociodemographic data, as well as information pertaining to drug use patterns, risk behaviours, and health care utilisation are collected. The survey for each study consists 
of a uniform set of questions, which permits the aggregation and analysis of data from all enrolled participants. Nurses collected blood specimens for HIV and hepatitis $\mathrm{C}$ serology and also provided basic medical care and referrals to appropriate health care services. Participants received $\$ 20$ for each study visit. All studies have been approved by the University of British Columbia/Providence Health Care Research Ethics Board.

\section{Study Sample}

Data from each cohort used in this analysis was collected during the same time frame; thus, all individuals were observed over the same follow-up period. All participants who completed a baseline survey between September 2005 and May 2008 were eligible for inclusion. At baseline, participants were asked to identify their biological sex at birth and their current sexual orientation. "Sexual minority status" was defined as answering affirmatively to one of: gay, lesbian, bisexual, transsexual, transgendered, or other. Participants who refused to report their sex at birth or current sexual and gender identity were excluded from this analysis.

\section{Study Hypotheses}

The primary hypothesis guiding this analysis was based on the risk environment framework and a careful assessment of prior literature investigating the relationship between MA use and HIV risk behaviour. We hypothesized that MA use among sexual minority drug users would be associated with differing exposure to individual, social, and structural HIV vulnerabilities. In an effort to build on previous studies $[16,23,24]$, we sought not only to examine individual-level HIV risk behaviour but also contextual factors including homelessness, neighbourhood of residence, the consumption of drugs in public, and the regulation of these spaces by law enforcement personnel. We also considered the relationship between MA use and physical violence and depression, which have been identified as independent risk factors for HIV infection $[9,25]$. Finally, we hypothesized that the relationship between MA use and these factors would differ significantly between sexual minority males and females.

\section{Variables of Interest}

The primary outcome of interest was ascertained by examining responses to the questions, "In the last six months, did you use non-injection crystal methamphetamine?" and "In the last six months, did you inject crystal methamphetamine?" Participants who responded "yes" to either or both questions were defined as crystal methamphetamine (MA) users in all subsequent analyses. We also determined the proportion of participants reporting daily or greater use of injection or non-injection MA use in the past 6 months, respectively. All variables examined in this study, including the outcomes and independent variables of interest, were assessed consistently and equivalently across all three studies.

Based on prior literature examining MA use among marginalised populations [12,26-29], we assessed as explanatory variables a broad set of sociodemographic characteristics, drug use variables, sexual activities, markers of violence and depression, and contextual factors. These variables were also chosen to represent both "micro"- (i.e., the immediate social environment of drug use) and "macro"- (i.e., the societal, economic, and legal context that structure drug use and harm) levels articulated by the risk environment framework [19]. Sociodemographic characteristics examined included age (per year older), Aboriginal ancestry (yes versus no), current relationship status (single/dating versus married/regular partner), and baseline HIV status (positive versus negative). All other variables (unless otherwise indicated) referred to behaviours or activities in the past 6 months since the date of the interview. Drug use variables assessed included other stimulant use (i.e., non-injection cocaine use and crack use, respectively), any injection drug use, experiencing a non-fatal overdose, and binge drug use. As defined previously [30], the latter was operationalised as the self-reported use of drugs more often than usual. We also examined the following sexual activities: number of casual or regular partners excluding those in the context of sex work ( $>1$ versus $\leq 1)$; any vaginal or anal unprotected intercourse with casual or regular partners (yes versus no); and sex trade work, defined as a categorical variable with "no" as the reference level and consistent condom use with all clients and any unprotected intercourse with clients as the second and third levels, respectively. We ascertained involvement in (i.e., committing) and exposure to (i.e., experiencing) physical violence (yes versus no). We also used the Center for Epidemiologic Studies Depression Scale (CES-D) with a cut-off of $\geq 16$ to measure the level of depressive symptomatology among participants [31]. Finally, contextual factors examined included: residency in the Downtown South (DTS), an area known as a mixed business and entertainment district that is also inhabited by a large street youth population [32]; homelessness (yes versus no); having a warrant or area restriction (i.e., "no go zone") impact access to services or influence where drugs are consumed or purchased (yes versus no); and using drugs in public spaces (>75\% of the time versus $\leq 75 \%$ of the time). Warrants and area restrictions are legal orders to restrict access to certain areas of the city, and are commonly issued by law enforcement personnel in an attempt to disrupt crime and reduce street level disorder [33]. 


\section{Statistical Analysis}

As a preliminary analysis, we compared the baseline sociodemographic characteristics and MA use patterns between heterosexual and sexual minority participants, stratified by biological sex at birth. The Pearson chisquare test was used to compare categorical variables and the Wilcoxon rank sum test was used for continuous variables. We then identified the longitudinal correlates of MA use by using generalized estimating equations (GEE) with a logit link for binary outcomes. GEE were appropriate for this analysis since the factors associated with recent MA use over the baseline and four follow-up periods were serial (i.e., time-dependent) variables. GEE account for the correlation between repeated measures for each subject; thus, valid estimates of association and standard errors are obtained [34]. Since GEE models incorporate periods during which participants report engaging and not engaging in the outcome, data from all baseline and follow-up interviews were used in this analysis.

Since a primary objective of this study was to determine whether the correlates of MA use differed between males and females, we stratified the analyses by biological sex at birth and constructed two multivariate models. We applied a modified backward stepwise procedure to select covariates based on two criteria: the Akaike information criterion (AIC) and type-III $p$-values [35]. Lower AIC values indicate a better overall fit and lower $p$-values indicate higher variable significance. Starting with a full model containing all variables that were significant in bivariate analyses at $p<0.10$, covariates were removed sequentially in order of decreasing $p$-values. To compensate for potential variations in recruitment and selection procedures between studies, we also adjusted each model for cohort of enrolment. At each step, the $p$-values of each variable and the overall AIC were recorded, with the final model having the lowest AIC. Statistical analysis was conducted using SAS version 9.1.3 (SAS Institute Inc., Cary, North Carolina, USA) and all $p$-values are two-sided.

\section{Results}

\section{Sample Characteristics}

Between September 2005 and May 2008, 2109 unique individuals were enrolled into the ARYS, VIDUS or ACCESS cohorts. A total of 14 (0.7\%) refused to report their sex at birth or current sexual/gender identity and were thus excluded for the analysis. Of the 2095 eligible participants, 1389 (66.3\%) were male and 706 (33.7\%) were female. Among all participants, the median age at baseline was 37.0 (IQR: 24.7 - 45.4) and 641 (30.6\%) were of Aboriginal ancestry. The majority identified their sexual or gender identity as heterosexual ( $n=$ $1847,88.2 \%)$, followed by bisexual ( $n=168,8.0 \%)$, gay
( $n=43,2.1 \%)$, lesbian $(n=9,0.4 \%)$, and transsexual, transgendered, or other $(n=28,1.3 \%)$. Among those who reported their biological sex at birth as female, 144 (20.4\%) identified as a sexual minority compared to only $7.5 \%(n=104)$ of biological males.

\section{Baseline Methamphetamine Use}

Sociodemographic characteristics and methamphetamine use patterns for males and females stratified by sexual orientation are displayed in Table 1. At baseline, sexual minority males were more likely to be younger (median $=33$ versus $39, p=0.001$ ), HIV positive (40.4\% versus $21.2 \%, p<0.001$ ), and of Aboriginal ancestry (40.4\% versus $23.7 \%, p<0.001)$. In contrast, sexual minority females were less likely to be of Aboriginal ancestry (33.3\% versus $43.9 \%, p=0.023$ ). Among both males and females, sexual minority participants were significantly more likely to report injection and non-injection MA use in the past 6 months (Table 1). Notably, over half (62.1\%) of sexual minority males reported recently using MA, and a significant proportion (16.7\%) reported injecting MA at least daily. Approximately half ( $n=142$, $57.3 \%$ ) of sexual minority participants reported having used MA for at least a year since the date of the baseline interview.

\section{Longitudinal Correlates of Methamphetamine Use}

In Table 2, we report the results of the longitudinal analysis examining the factors associated with MA use among sexual minority males. Bivariate analyses indicated that male MA users were more likely to experience a variety of sexual HIV risks and vulnerabilities, including for example multiple recent sex partners (odds ratio $[\mathrm{OR}]=1.91, p=0.002$ ), unprotected intercourse $(\mathrm{OR}=1.86, p=0.004)$, and unprotected intercourse in the context of sex work $(\mathrm{OR}=3.25, p=$ $0.005)$. MA using men were also more likely to report injection drug use $(\mathrm{OR}=2.31, p=0.004)$, experience physical violence $(\mathrm{OR}=1.76, p=0.004)$, commit physical violence $(\mathrm{OR}=1.90, p=0.025)$ and exhibit depressive symptoms $(\mathrm{OR}=1.79, p=0.010)$. In multivariate analysis, independent correlates of MA use among sexual minority males included: younger age (adjusted odds ratio $[\mathrm{AOR}]=0.93, p=0.011)$, Aboriginal ancestry $(\mathrm{AOR}=2.59, p=0.019)$, injection drug use (adjusted odds ratio $[\mathrm{AOR}]=3.98, p<0.001)$, unprotected sexual intercourse $(\mathrm{AOR}=1.62, p=0.048)$, increased depressive symptoms $(\mathrm{AOR}=1.67, p=0.044)$, and having an area restriction impact access to services or influence where drugs are used or purchased $(\mathrm{AOR}=4.18, p=$ 0.008).

Increased sexual HIV vulnerabilities were also observed among MA-using sexual minority females (Table 3). For example, females reporting recent MA 
Table 1 Baseline sociodemographic characteristics and methamphetamine use patterns among ARYS, VIDUS, and ACCESS participants, stratified by biological sex at birth and self-identified sexual orientation $(\mathrm{n}, \%$ unless otherwise indicated)

\begin{tabular}{|c|c|c|c|c|c|c|c|c|}
\hline \multirow{2}{*}{ Characteristic } & \multicolumn{4}{|c|}{ Male $(N=1389)$} & \multicolumn{4}{|c|}{ Female $(N=706)$} \\
\hline & $\begin{array}{l}\text { Sexual Minority* } \\
(n=104)\end{array}$ & $\begin{array}{l}\text { Heterosexual } \\
(n=1285)\end{array}$ & $\begin{array}{l}\text { OR } \\
(95 \% \mathrm{Cl})\end{array}$ & $\begin{array}{l}p- \\
\text { value }\end{array}$ & $\begin{array}{l}\text { Sexual Minority* } \\
(n=144)\end{array}$ & $\begin{array}{l}\text { Heterosexual } \\
(n=562)\end{array}$ & $\begin{array}{l}\text { OR }(95 \% \\
\mathrm{Cl})\end{array}$ & $\begin{array}{l}p- \\
\text { value }\end{array}$ \\
\hline Age (median, IQR) & $33(24-42)$ & $39(25-47)$ & $\begin{array}{r}0.97(0.95- \\
0.99)\end{array}$ & 0.001 & $31(23-41)$ & $35(24-44)$ & $\begin{array}{r}0.98(0.97- \\
1.00)\end{array}$ & 0.053 \\
\hline \multicolumn{9}{|l|}{ Aboriginal ancestry } \\
\hline Yes & $42(40.4)$ & $305(23.7)$ & $\begin{array}{r}2.18(1.44- \\
3.29)\end{array}$ & $<0.001$ & $48(33.3)$ & $246(43.9)$ & $\begin{array}{r}0.64(0.44- \\
0.94)\end{array}$ & 0.023 \\
\hline No & $62(59.6)$ & $980(76.3)$ & & & $96(66.7)$ & $315(56.2)$ & & \\
\hline \multicolumn{9}{|l|}{ Relationship status } \\
\hline Single/dating & $73(70.2)$ & $927(72.4)$ & $\begin{array}{r}0.90(0.58- \\
1.39)\end{array}$ & 0.634 & $90(62.5)$ & 307 (55.4) & $\begin{array}{r}1.34(0.92- \\
1.95)\end{array}$ & 0.127 \\
\hline $\begin{array}{l}\text { Married/regular } \\
\text { partner }\end{array}$ & $31(29.8)$ & $354(27.6)$ & & & $54(37.5)$ & $247(44.6)$ & & \\
\hline \multicolumn{9}{|l|}{ HIV status } \\
\hline Positive & $42(40.4)$ & $272(21.2)$ & $\begin{array}{r}2.52(1.67- \\
3.82)\end{array}$ & $<0.001$ & $41(28.5)$ & $159(28.3)$ & $\begin{array}{r}1.01(0.67- \\
1.51)\end{array}$ & 0.966 \\
\hline Negative & $62(59.6)$ & $1013(78.8)$ & & & $103(71.5)$ & $403(71.7)$ & & \\
\hline \multicolumn{9}{|l|}{ Any meth use ${ }^{\dagger}$} \\
\hline Yes & $64(62.1)$ & $388(30.5)$ & $\begin{array}{r}3.74(2.47- \\
5.67)\end{array}$ & $<0.001$ & $58(40.3)$ & $150(27.2)$ & $\begin{array}{r}1.80(1.23- \\
2.64)\end{array}$ & 0.003 \\
\hline No & 39 (37.9) & $884(69.5)$ & & & $86(59.7)$ & $401(72.8)$ & & \\
\hline \multicolumn{9}{|l|}{$\begin{array}{l}\text { Any non-injection } \\
\text { meth use }\end{array}$} \\
\hline Yes & $38(36.5)$ & $223(17.5)$ & $\begin{array}{r}2.71(1.78- \\
4.15)\end{array}$ & $<0.001$ & $36(25.0)$ & $89(16.0)$ & $\begin{array}{r}1.75(1.12- \\
2.71)\end{array}$ & 0.013 \\
\hline No & $66(63.5)$ & $1050(82.5)$ & & & $108(75.0)$ & $466(84.0)$ & & \\
\hline \multicolumn{9}{|l|}{$\begin{array}{l}\text { Daily non-injection } \\
\text { meth use }^{\dagger}\end{array}$} \\
\hline Yes & $11(10.6)$ & $39(3.1)$ & $\begin{array}{r}3.72(1.84- \\
7.50)\end{array}$ & $<0.001$ & $8(5.6)$ & $20(3.7)$ & $\begin{array}{r}1.56(0.67- \\
3.62)\end{array}$ & 0.296 \\
\hline No & $93(89.4)$ & $1226(96.9)$ & & & $135(94.4)$ & $527(96.3)$ & & \\
\hline \multicolumn{9}{|l|}{$\begin{array}{l}\text { Any injection meth } \\
\text { use }^{+}\end{array}$} \\
\hline Yes & $43(41.4)$ & $262(20.4)$ & $\begin{array}{r}2.75(1.82- \\
4.15)\end{array}$ & $<0.001$ & $39(27.1)$ & $100(18.0)$ & $\begin{array}{r}1.69(1.10- \\
2.59)\end{array}$ & 0.016 \\
\hline No & $61(58.6)$ & $1021(79.6)$ & & & $105(72.9)$ & $455(82.0)$ & & \\
\hline \multicolumn{9}{|l|}{$\begin{array}{l}\text { Daily injection meth } \\
\text { use }^{f}\end{array}$} \\
\hline Yes & 17 (16.7) & $45(3.5)$ & $\begin{array}{r}5.45(3.00- \\
9.95)\end{array}$ & $<0.001$ & $9(6.4)$ & $16(2.9)$ & $\begin{array}{r}2.27(0.98- \\
5.24)\end{array}$ & 0.066 \\
\hline No & 85 (83.3) & 1229 (96.5) & & & 132 (93.6) & 532 (97.1) & & \\
\hline
\end{tabular}

Notes: * "sexual minority" refers to lesbian, gay, bisexual, transgendered, transsexual, or other orientation; † refers to activities in the past 6 months.

use were more likely to have multiple regular or casual sex partners $(\mathrm{OR}=1.55, p=0.029)$. Several associations that were observed among MA-using males were also significant among females. For example, female MA users were younger ( $\mathrm{OR}=0.95, p=0.005)$, more likely to inject drugs $(\mathrm{OR}=1.68, p=0.011)$, and reported elevated rates of unprotected intercourse in the context of sex work ( $\mathrm{OR}=3.27, p=0.001)$. In contrast, MA-using females were less likely to be of Aboriginal ancestry (OR $=0.41, p=0.012$ ).
In a multivariate analysis, several unique correlates of MA use emerged among sexual minority females. In contrast to males, MA-using females were more likely to reside in the Downtown South neighbourhood (AOR $=1.60, p=0.047$ ). Furthermore, MA use among sexual minority females was independently associated with unprotected intercourse with sex trade clients (AOR = 2.62, $p=0.027$ ). Similar to males, MA-using females were more likely to report injection drug use $(\mathrm{AOR}=$ 2.49, $p=0.002$ ). 
Table 2 Longitudinal analysis of factors associated with crystal methamphetamine use (n= 104)

\begin{tabular}{|c|c|c|c|c|c|c|}
\hline \multirow[b]{2}{*}{ Characteristic } & \multicolumn{3}{|c|}{ Bivariate } & \multicolumn{3}{|c|}{ Multivariate } \\
\hline & Odds Ratio & $95 \% \mathrm{Cl}$ & $p$-value & Adjusted Odds Ratio & $95 \% \mathrm{Cl}$ & $p$-value \\
\hline \multicolumn{7}{|l|}{ Sociodemographic Characteristics } \\
\hline Age (per year) & 0.92 & $0.89-0.96$ & $<0.001$ & 0.93 & $0.88-0.98$ & 0.011 \\
\hline Aboriginal ancestry (yes vs. no) & 2.37 & $1.17-4.79$ & 0.016 & 2.59 & $1.17-5.77$ & 0.019 \\
\hline Relationship status (single/dating vs. married/partner) & 0.96 & $0.65-1.42$ & 0.842 & & & \\
\hline HIV Status (positive vs. negative) & 0.50 & $0.24-1.00$ & 0.051 & & & \\
\hline \multicolumn{7}{|l|}{ Drug Use } \\
\hline Non-injection cocaine use ${ }^{\dagger}$ (yes vs. no) & 2.44 & $1.09-5.44$ & 0.029 & & & \\
\hline Crack use $^{\dagger}$ (yes vs. no) & 1.47 & $0.89-2.43$ & 0.133 & & & \\
\hline Any injection drug use ${ }^{\dagger}$ (yes vs. no) & 2.31 & $1.30-4.11$ & 0.004 & 3.98 & $1.85-8.57$ & $<0.001$ \\
\hline Overdose $^{\dagger}$ (yes vs. no) & 1.52 & $0.83-2.77$ & 0.172 & & & \\
\hline Binge drug use ${ }^{\dagger}$ (yes vs. no) & 1.50 & $0.90-2.50$ & 0.118 & & & \\
\hline \multicolumn{7}{|l|}{ Sexual Activities } \\
\hline Number of sex partners ${ }^{\dagger}(>1$ vs. $\leq 1)$ & 1.91 & $1.28-2.86$ & 0.002 & & & \\
\hline Unprotected intercourse ${ }^{\dagger}$ (yes vs. no) & 1.86 & $1.22-2.84$ & 0.004 & 1.62 & $1.01-2.60$ & 0.048 \\
\hline \multicolumn{7}{|l|}{ Sex trade work $^{\dagger}$ (ref = no sex trade work) } \\
\hline Consistent condom use with clients $^{\dagger}$ (yes vs. ref) & 2.79 & $1.62-4.82$ & $<0.001$ & & & \\
\hline Any unprotected sex with clients ${ }^{\dagger}$ (yes vs. ref) & 3.25 & $1.44-7.37$ & 0.005 & & & \\
\hline \multicolumn{7}{|l|}{ Violence \& Depression } \\
\hline Experience physical violence ${ }^{\dagger}$ (yes vs. no) & 1.76 & $1.20-2.59$ & 0.004 & 1.47 & $0.93-2.32$ & 0.100 \\
\hline Commit physical violence ${ }^{\dagger}$ (yes vs. no) & 1.90 & $1.09-3.31$ & 0.025 & & & \\
\hline Clinical depression $\left(C E S-D^{\ddagger} \geq 16\right.$ vs. $\left.<16\right)$ & 1.79 & $1.15-2.79$ & 0.010 & 1.67 & $1.01-2.76$ & 0.044 \\
\hline \multicolumn{7}{|l|}{ Contextual Factors } \\
\hline Downtown South residency (yes vs. no) & 1.45 & $0.90-2.34$ & 0.124 & & & \\
\hline Homeless $^{\dagger}$ (yes vs. no) & 1.76 & $1.00-3.09$ & 0.050 & & & \\
\hline Area restrictions influence drug use (yes vs. no) & 4.02 & $0.87-18.54$ & 0.075 & 4.18 & $1.46-11.95$ & 0.008 \\
\hline Use drugs in public ${ }^{\dagger}$ (>75\% vs. $\leq 75 \%$ of the time) & 1.53 & $0.96-2.43$ & 0.073 & & & \\
\hline
\end{tabular}

Notes: model adjusted for cohort of recruitment; * "sexual minority" refers to lesbian, gay, bisexual, transgendered, transsexual, or other orientation; $\dagger$ refers to activities in the past 6 months; $\neq$ CES-D refers to the Center for Epidemiologic Studies Depression Scale.

\section{Discussion}

In the current study, we observed a high prevalence of MA use among sexual minority males and females in comparison to heterosexual participants. We also found that, consistent with the risk environment framework, MA use was associated with an array of individual, social, and contextual HIV-related risks and vulnerabilities among sexual minority drug users.

Although some correlates of MA use (e.g., younger age and injection drug use) were significant for both sexes, several important differences were observed. For example, unprotected intercourse involving regular or casual partners was more common among males who reported using methamphetamine, while unprotected intercourse in the context of sex work was associated with MA use among females. Furthermore, only MAusing males were more likely to experience depressive symptoms and report having area restrictions (i.e., "no go" zones) impact access to services of influence where drugs are used or purchased. These findings may be due to the fact that sexual minority males reported heavier MA use patterns compared to females, and thus may be more likely to experience individual (i.e., depressive symptoms) and contextual (i.e., exposure to law enforcement) MA-related sequelae. Finally, Aboriginal ancestry was positively associated with MA use among males but inversely associated with MA use among females.

Consistent with other studies $[7,8,36]$, MA use was linked with unprotected intercourse among sexual minority men. Although we were unable to ascertain the context in which instances of unprotected intercourse occurred, we point to other research indicating that homeless sexual minority males frequently experience sexual victimization and abuse from partners [37]. Although more research is required to fully elucidate casual mechanisms, we hypothesize that the relationship between sexual risk and MA use observed among this sample of street-involved sexual minority men is less a function of desire to enhance sex but is in fact a marker of increased vulnerability within sexual relationships. 
Table 3 Longitudinal analysis of factors associated with crystal methamphetamine usef among sexual minority* females $(n=144)$

\begin{tabular}{|c|c|c|c|c|c|c|}
\hline \multirow[b]{2}{*}{ Characteristic } & \multicolumn{3}{|c|}{ Bivariate } & \multicolumn{3}{|c|}{ Multivariate } \\
\hline & Odds Ratio & $95 \% \mathrm{Cl}$ & $p$-value & Adjusted Odds Ratio & $95 \% \mathrm{Cl}$ & $p$-value \\
\hline \multicolumn{7}{|l|}{ Sociodemographic Characteristics } \\
\hline Age (per year) & 0.95 & $0.92-0.99$ & 0.005 & & & \\
\hline Aboriginal ancestry (yes vs. no) & 0.41 & $0.21-0.82$ & 0.012 & 0.55 & $0.25-1.21$ & 0.137 \\
\hline Relationship (single/dating vs. married/partner) & 1.07 & $0.76-1.49$ & 0.708 & & & \\
\hline HIV Status (positive vs. negative) & 0.62 & $0.90-1.30$ & 0.209 & & & \\
\hline \multicolumn{7}{|l|}{ Drug Use } \\
\hline Non-injection cocaine use $e^{\dagger}$ yes vs. no) & 1.79 & $1.06-3.04$ & 0.030 & 1.66 & $0.94-2.92$ & 0.079 \\
\hline Crack use $^{\dagger}$ (yes vs. no) & 0.95 & $0.71-1.27$ & 0.730 & & & \\
\hline Any injection drug use ${ }^{\dagger}$ (yes vs. no) & 1.68 & $1.13-2.50$ & 0.011 & 2.49 & $1.42-4.39$ & 0.002 \\
\hline Overdose $^{\dagger}$ (yes vs. no) & 1.47 & $0.90-2.41$ & 0.126 & & & \\
\hline Binge drug use ${ }^{\dagger}$ (yes vs. no) & 1.18 & $0.77-1.81$ & 0.452 & & & \\
\hline \multicolumn{7}{|l|}{ Sexual Activities } \\
\hline Number of sex partners ${ }^{\dagger}(>1$ vs. $\leq 1)$ & 1.55 & $1.05-2.30$ & 0.029 & & & \\
\hline Unprotected intercourse ${ }^{\dagger}$ (yes vs. no) & 0.97 & $0.65-1.45$ & 0.897 & & & \\
\hline \multicolumn{7}{|l|}{ Sex trade work $^{\dagger}$ (ref = no sex trade work) } \\
\hline Consistent condom use with clients ${ }^{\dagger}$ (yes vs. ref) & 1.30 & $0.88-1.93$ & 0.189 & 1.16 & $0.72-1.87$ & 0.543 \\
\hline Any unprotected sex with clients ${ }^{\dagger}$ (yes vs. ref) & 3.27 & $1.60-6.68$ & 0.001 & 2.62 & $1.12-6.14$ & 0.027 \\
\hline \multicolumn{7}{|l|}{ Violence \& Depression } \\
\hline Experience physical violence ${ }^{\dagger}$ (yes vs. no) & 1.24 & $0.88-1.75$ & 0.210 & & & \\
\hline Commit physical violence ${ }^{\dagger}$ (yes vs. no) & 1.12 & $0.81-1.54$ & 0.499 & & & \\
\hline Clinical depression $\left(C E S-D^{\ddagger} \geq 16\right.$ vs. $\left.<16\right)$ & 0.85 & $0.66-1.09$ & 0.204 & & & \\
\hline \multicolumn{7}{|l|}{ Contextual Factors } \\
\hline Downtown South residency (yes vs. no) & 1.45 & $1.00-2.10$ & 0.053 & 1.60 & $1.01-2.54$ & 0.047 \\
\hline Homeless $^{\dagger}$ (yes vs. no) & 1.19 & $0.86-1.64$ & 0.299 & & & \\
\hline Area restrictions influence drug use (yes vs. no) & 0.59 & $0.28-1.23$ & 0.160 & & & \\
\hline Use drugs in public ${ }^{\dagger}$ ( $>75 \%$ vs. $\leq 75 \%$ of the time) & 1.18 & $0.77-1.81$ & 0.446 & & & \\
\hline
\end{tabular}

Notes: model adjusted for cohort of recruitment; * "sexual minority" refers to lesbian, gay, bisexual, transgendered, transsexual, or other orientation; † refers to activities in the past 6 months; $\neq$ CES-D refers to the Center for Epidemiologic Studies Depression Scale.

A similar pathway may also explain the marginal association between MA use and experiencing physical violence observed among males in this study.

In multivariate analysis, among the subsample of females engaging in sex work, MA use was associated with unprotected intercourse with clients. This finding can be situated within a growing literature demonstrating how social and structural inequities hinder the individual agency of drug-using survival sex workers to practice HIV prevention and harm reduction with clients [38]. In a recent study of female sex workers (FSW) in Vancouver, Canada, Shannon et al. [39] demonstrated that MA use is associated with living and working in marginalised public spaces (e.g., industrial areas). These areas have been shown in previous research to be settings of increased risk of violence and pressure from clients to engage in unprotected sex [40]. Our results support this work and indicate that MA use may augment the adverse impact of social-structural factors in the production of HIV risk among sexual minority women involved in survival sex work.

The strongest correlate of MA use among sexual minority men was reporting that a warrant or area restriction impacted access to services or influenced where drugs are consumed or purchased. The socio-legal regulation of public space and its negative impact on the health of homeless people and street-level drug users has been described previously [41]. Recent work also suggests that the displacement of street-involved young people using warrants or area restrictions exacerbates stigma and increases sexual vulnerability and HIV risk [42]. Our findings suggest that having one's movements restricted may also encourage transitions in drug use (including initiation of MA use), due perhaps to the forced removal of drug users from normative environments and social networks. It is also possible that MA users are at an increased risk of incarceration and other interactions with the legal system, and are thus more 
likely to be affected by punitive policies such as warrants and area restrictions. This form of marginalisation (produced by policies and practices meant to reduce exposure to street-level drug use and violence) is one example of a population-level intervention that may exacerbate inequity and worsen the health of vulnerable groups [43].

These findings also support the urgent need for increased resources and programming directed towards LGBT people who use methamphetamine. In order to inform more effective interventions to reduce the harms associated with MA, researchers must clearly articulate how social/structural processes impact the health of sexual minorities. Once clearly identified, these factors can then be the target of broad sets of evidence-based interventions to reduce health inequities and improve overall health. For example, changes in government policy along with community mobilization and solidarity programs have been shown to be highly successful at reducing HIV risk among survival sex workers [44]. Programs that support capacity-building in marginalised communities have also been shown to reduce health inequity and improve health outcomes [45]. Although further research is required to elucidate the potential impact of specific enforcement practices (e.g., area restrictions) on MA use and related harms, improved coordination between policing and public health initiatives may represent another opportunity to prevent the (un)-intended consequences of public policies meant to reduce crime and street disorder [46]. Finally, additional research is required to identify specific programmatic needs of subpopulations within sexual minority communities, including for example transgendered youth.

To complement structural interventions, some behavioural approaches (e.g., cognitive behavioural therapy) offer promise [47]. For example, LGBT-specific substance abuse treatment programs have been found to reduce engagement in high-risk sex among drug-using gay men [48]. Harm reduction programs, particularly those offering tailored services for MA users, are effective and well received by clients [49]. Finally, given the associations between Aboriginal ancestry, sexual orientation, and MA use observed in this study, methamphetamine-specific programming should carefully identify the manner in which cultural and sexual identities shape drug use and HIV risk within specific contexts and settings.

This study has a number of limitations that should be noted. The ARYS, VIDUS, and ACCESS cohorts are not random samples of the eligible population; thus, findings may not necessarily be generalizable to other urban areas in which MA use is prevalent. The small sample sizes may have resulted in insufficient power to detect true associations, particularly after adjustment for confounding. Furthermore, data from three studies with different inclusion criteria were combined and analysed, which may have resulted in cohort or selection effects. To mitigate the potential impact of these biases, all sampling and data collection procedures were harmonized, and all multivariate models were adjusted for cohort of recruitment. We note that all behaviours ascertained in this study were self-reported, and we were unable to confirm MA use with urine samples or other measures. We also recognize that our primary analysis was restricted to individuals who self-identified as a sexual minority; therefore, heterosexual-identified individuals who engaged in same-sex activity were excluded. We chose not to rely on behavioural eligibility criteria (e.g., MSM), as we feel, as do others [50], that ignoring sexual identity in HIV prevention efforts obscures the social dimensions of sexuality that are critical for the development of effective and culturally relevant public health interventions. However, we note that public health efforts should be made to provide appropriate services for non-LGBT identifying MSM/WSW, including programs that explicitly acknowledge and accept diverse sexual experiences and identities [51]. We were unable to ascertain motivations for MA use, which if examined may have accounted some of the observed differences in the characteristics and consequences of MA use between male and female participants in this study. Finally, although our data are longitudinal, we do not wish to imply that this analysis provides thorough insight into the causal pathways linking MA use and HIV risk with broader social and structural inequities.

\section{Conclusion}

We have demonstrated in a longitudinal data set a high prevalence of MA use among a cohort of street-involved sexual minority drug users. To our knowledge, this is the first study to extend the risk environment approach as a theoretical foundation from which to understand the contexts of risk associated with MA use among LGBT populations. Consistent with the risk environment framework, MA use was associated with distinct sets of individual, social, and structural HIV risks and vulnerabilities among women and men, respectively; therefore, comprehensive interventions that involve sectors outside of health (e.g., housing, law enforcement), in addition to drug-specific approaches tailored to LGBT populations, are required to reduce HIV vulnerability and MA-related harms. Finally, researchers and public health practitioners must identify multi-sector population-level interventions that do not exacerbate inequity but successfully mitigate health inequities among vulnerable populations. 


\section{Acknowledgements}

The authors thank the study participants for their contribution to the research, as well as current and past investigators and staff. We would specifically like to thank Deborah Graham, Peter Vann, Caitlin Johnston, Steve Kain, and Calvin Lai for their research and administrative assistance. The ARYS study was supported by the US National Institutes of Health $(\mathrm{NIH})$ grant R01-DA028532 as well as the Canadian Institutes of Health Research (CIHR) grant MOP-102742. The VIDUS study was supported by NIH (R01DA011591). The ACCESS study was supported by NIH (R01-DA021525) and CIHR (MOP-79297). All studies are supported by a CIHR team grant RAA79918. TK is supported by the Michael Smith Foundation for Health Research (MSFHR) and the CIHR. BDLM is supported by senior graduate trainee awards from MSFHR and CIHR

\section{Author details}

'British Columbia Centre for Excellence in HIV/AIDS, St. Paul's Hospital, 6081081 Burrard Street, Vancouver, BC, V6Z 1Y6, Canada. ${ }^{2}$ School of Population and Public Health, University of British Columbia, 2206 East Mall, Vancouver BC, V6T 1Z3, Canada. ${ }^{3}$ Department of Medicine, University of British Columbia, St. Paul's Hospital, 608-1081 Burrard Street, Vancouver, BC, V6Z 1Y6, Canada. ${ }^{4}$ Department of Psychiatry, University of California, 9500 Gilman Drive, La Jolla, California, 92093-0680, USA.

\section{Authors' contributions}

TK had full access to all of the data and takes responsibility for the integrity of the results and the accuracy of the statistical analysis. BM, TK, and JS conceived the study concept and design, and BM was responsible for the statistical analysis and composition of the manuscript. BM led the interpretation of the results, with significant scientific input from JS, EW, TP, $J M$, and TK. The manuscript was edited and revised by BM, EW, JS, TP, JM, and TK. All authors read and approved the final version of the manuscript.

\section{Competing interests}

Dr Montaner reported receiving educational grants from and serving as an ad hoc advisor to or speaking at various events sponsored by Abbott Laboratories, Agouron Pharmaceuticals Inc, Boehringer Ingelheim Pharmaceuticals Inc, Borean Pharma AS, Bristol-Myers Squibb, DuPont Pharma, Gilead Sciences, GlaxoSmithKline, Hoffmann-La Roche, Immune Response Corporation, Incyte, Janssen-Ortho Inc, Kucera Pharmaceutical Company, Merck Frosst Laboratories, Pfizer Canada Inc, Sanofi Pasteur, Shire Biochem Inc, Tibotec Pharmaceuticals Ltd, and Trimeris Inc. All other authors declare that they have no competing interests.

Received: 28 July 2010 Accepted: 7 January 2011

Published: 7 January 2011

\section{References}

1. Mayer KH, Bradford JB, Makadon HJ, Stall R, Goldhammer H, Landers S: Sexual and gender minority health: what we know and what needs to be done. Am J Public Health 2008, 98:989-995.

2. Dean L, Meyer IH, Robinson K, Sell RL, Sember R, Silenzio VMB, Bowen DJ, Bradford J, Rothblum E, White J, et al: Lesbian, gay, bisexual, and transgender health: findings and concerns. J Gay Lesbian Med Assoc 2002, 4:102-151.

3. Mays VM, Yancey AK, Cochran SD, Weber M, Fielding JE: Heterogeneity of health disparities among African American, Hispanic, and Asian American women: unrecognized influences of sexual orientation. Am J Public Health 2002, 92:632-639.

4. Wolitski RJ, Stall R, Valdiserri RO: Unequal Opportunity: Health Disparities Affecting Gay and Bisexual Men in the United States New York, NY: Oxford University Press; 2007.

5. Hughes TL, Eliason M: Substance use and abuse in lesbian, gay, bisexual and transgender populations. J Prim Prev 2002, 22:263-298.

6. McCabe SE, Hughes TL, Bostwick WB, West BT, Boyd CJ: Sexual orientation, substance use behaviors and substance dependence in the United States. Addiction 2009, 104:1333-1345.

7. Halkitis PN, Parsons JT, Stirratt MJ: A double epidemic: crystal methamphetamine drug use in relation to HIV transmission among gay men. J Homosex 2001, 41:17-35.
8. Frosch D, Shoptaw S, Huber A, Rawson RA, Ling W: Sexual HIV risk among gay and bisexual male methamphetamine abusers. I Subst Abuse Treat 1996, 13:483-486.

9. Koblin BA, Husnik MJ, Colfax G, Huang Y, Madison M, Mayer K, Barresi PJ, Coates TJ, Chesney MA, Buchbinder S: Risk factors for HIV infection among men who have sex with men. AIDS 2006, 20:731-739.

10. Parsons JT, Kelly BC, Wells BE: Differences in club drug use between heterosexual and lesbian/bisexual females. Addict Behav 2006, 31:2344-2349.

11. Lampinen TM, McGhee D, Martin I: Increased risk of "club" drug use among gay and bisexual high school students in British Columbia. J Adolesc Health 2006, 38:458-461.

12. Lorvick J, Martinez A, Gee L, Kral AH: Sexual and injection risk among women who inject methamphetamine in San Francisco. J Urban Health 2006, 83:497-505.

13. Dluzen DE, Liu B: Gender differences in methamphetamine use and responses: A review. Gend Med 2008, 5:24-35.

14. Semple SJ, Patterson TL, Grant I: Motivations associated with methamphetamine use among HIV+ men who have sex with men. J Subst Abuse Treat 2002, 22:149-156.

15. Halkitis PN, Shrem MT: Psychological differences between binge and chronic methamphetamine using gay and bisexual men. Addict Behav 2006, 31:549-552.

16. Garofalo R, Mustanski BS, McKirnan DJ, Herrick A, Donenberg GR: Methamphetamine and young men who have sex with men: understanding patterns and correlates of use and the association with HIV-related sexual risk. Arch Pediatr Adolesc Med 2007, 161:591-596.

17. Colfax G, Santos GM, Chu P, Vittinghoff E, Pluddemann A, Kumar S, Hart C: Amphetamine-group substances and HIV. Lancet 2010, 376:458-474.

18. Semple SJ, Strathdee SA, Zians J, Patterson TL: Factors associated with sex in the context of methamphetamine use in different sexual venues among HIV-positive men who have sex with men. BMC Public Health 2010, 10:178.

19. Rhodes T: The 'risk environment': a framework for understanding and reducing drug-related harm. Int I Drug Policy 2002, 13:85-94.

20. Tyndall MW, Currie S, Spittal P, Li K, Wood E, O'Shaughnessy MV, Schechter MT: Intensive injection cocaine use as the primary risk factor in the Vancouver HIV-1 epidemic. AIDS 2003, 17:887-893.

21. Strathdee SA, Palepu A, Cornelisse PG, Yip B, O'Shaughnessy MV, Montaner JS, Schechter MT, Hogg RS: Barriers to use of free antiretroviral therapy in injection drug users. JAMA 1998, 280:547-549.

22. Wood E, Stoltz JA, Montaner JS, Kerr T: Evaluating methamphetamine use and risks of injection initiation among street youth: The ARYS study. Harm Reduct J 2006, 3:18.

23. Plankey MW, Ostrow DG, Stall R, Cox C, Li X, Peck JA, Jacobson LP: The relationship between methamphetamine and popper use and risk of HIV seroconversion in the multicenter AIDS cohort study. J Acquir Immune Defic Syndr 2007, 45:85-92.

24. Gleghorn AA, Marx R, Vittinghoff E, Katz MH: Association between drug use patterns and HIV risks among homeless, runaway, and street youth in northern California. Drug Alcohol Depend 1998, 51:219-227.

25. Dunkle KL, Jewkes RK, Brown HC, Gray GE, McIntryre JA, Harlow SD: Gender-based violence, relationship power, and risk of HIV infection in women attending antenatal clinics in South Africa. Lancet 2004, 363:1415-1421.

26. Wood E, Stoltz JA, Zhang R, Strathdee SA, Montaner JSG, Kerr T: Circumstances of first crystal methamphetamine use and initiation of injection drug use among high-risk youth. Drug Alcohol Rev 2008, 27:270-276.

27. Rusch ML, Lozada R, Pollini RA, Vera A, Patterson TL, Case P, Strathdee SA: Polydrug use among IDUs in Tijuana, Mexico: correlates of methamphetamine use and route of administration by gender. J Urban Health 2009, 86:760-775.

28. Jaffe A, Shoptaw S, Stein J, Reback CJ, Rotheram-Fuller E: Depression ratings, reported sexual risk behaviors, and methamphetamine use: latent growth curve models of positive change among gay and bisexual men in an outpatient treatment program. Exp Clin Psychopharmacol 2007, 15:301-307.

29. Semple SJ, Patterson TL, Grant I: A comparison of injection and noninjection methamphetamine-using HIV positive men who have sex with men. Drug Alcohol Depend 2004, 76:203-212. 
30. Miller CL, Kerr T, Frankish JC, Spittal PM, Li K, Schechter MT, Wood E: Binge drug use independently predicts HIV seroconversion among injection drug users: implications for public health strategies. Subst Use Misuse 2006, 41:199-210.

31. Radloff LS: The CES-D Scale: A self-report depression scale for research in the general population. Appl Psych Meas 1977, 1:385-401.

32. Fast D, Small W, Wood E, Kerr T: Coming 'down here': young people's reflections on becoming entrenched in a local drug scene. Soc Sci Med 2009, 69:1204-1210.

33. Dandurand Y, Griffiths C, Chin V, Chan J: Confident policing in a troubled community: Evaluation of the Vancouver Policy Department's city-wide enforcement team initiative Vancouver, BC: University College of the Fraser Valley; 2004.

34. Liang KY, Zeger SL: Longitudinal data analysis using generalized linear models. Biometrika 1986, 73:13-22.

35. Harrell FE: Regression modeling strategies with applications to linear models, logistic regression, and survival analysis New York, NY: Springer Series in Statistics; 2001

36. Mansergh G, Shouse RL, Marks G, Guzman R, Rader M, Buchbinder S, Colfax GN: Methamphetamine and sildenafil (Viagra) use are linked to unprotected receptive and insertive anal sex, respectively, in a sample of men who have sex with men. Sex Transm Infect 2006, 82:131-134.

37. Cochran BN, Stewart AJ, Ginzler JA, Cauce AM: Challenges faced by homeless sexual minorities: Comparison of gay, lesbian, bisexual, and transgender homeless adolescents with their heterosexual counterparts. Am J Public Health 2002, 92:773-777.

38. Shannon K, Kerr T, Allinott S, Chettiar J, Shoveller J, Tyndall MW: Social and structural violence and power relations in mitigating HIV risk of drugusing women in survival sex work. Soc Sci Med 2008, 66:911-921.

39. Shannon K, Strathdee S, Shoveller JA, Zhang R, Montaner JSG, Tyndall M: Crystal methamphetamine use among female street-based sex workers: Moving beyond individual-focused interventions. Drug Alcohol Depend 2011, 113:76-81.

40. Shannon K, Strathdee SA, Shoveller J, Rusch M, Kerr T, Tyndall MW: Structural and environmental barriers to condom use negotiation with clients among female sex workers: implications for HIV-prevention strategies and policy. Am J Public Health 2009, 99:659-665.

41. Rhodes T, Kimber J, Small W, Fitzgerald J, Kerr T, Hickman M, Holloway G: Public injecting and the need for 'safer environment interventions' in the reduction of drug-related harm. Addiction 2006, 101:1384-1393.

42. Marshall BDL, Kerr T, Shoveller JA, Montaner JS, Wood E: Structural factors associated with an increased risk of HIV and sexually transmitted infection transmission among street-involved youth. BMC Public Health 2009, 9:7.

43. Frohlich $\mathrm{KL}$, Potvin $\mathrm{L}$ : Transcending the known in public health practice: the inequality paradox: the population approach and vulnerable populations. Am J Public Health 2008, 98:216-221.

44. Kerrigan D, Moreno L, Rosario S, Gomez B, Jerez H, Barrington C, Weiss E, Sweat M: Environmental-structural interventions to reduce HIV/STI risk among female sex workers in the Dominican Republic. Am J Public Health 2006, 96:120-125.

45. Bradley BS, Deighton J, Selby J: The 'Voices' project: capacity-building in community development for youth at risk. J Health Psychol 2004, 9:197-212.

46. DeBeck K, Wood E, Zhang R, Tyndall M, Montaner J, Kerr T: Police and public health partnerships: Evidence from the evaluation of Vancouver's supervised injection facility. Subst Abuse Treat Prev Policy 2008, 3:11.

47. Shoptaw S, Reback CJ, Peck JA, Yang X, Rotheram-Fuller E, Larkins S, Veniegas RC, Freese TE, Hucks-Ortiz C: Behavioral treatment approaches for methamphetamine dependence and HIV-related sexual risk behaviors among urban gay and bisexual men. Drug Alcohol Depend 2005, 78:125-134.

48. Reback CJ, Larkins S, Shoptaw S: Changes in the meaning of sexual risk behaviors among gay and bisexual male methamphetamine abusers before and after drug treatment. AIDS Behav 2004, 8:87-98.

49. Mausbach BT, Semple SJ, Strathdee SA, Zians J, Patterson TL: Efficacy of a behavioral intervention for increasing safer sex behaviors in HIV-positive MSM methamphetamine users: results from the EDGE study. Drug Alcohol Depend 2007, 87:249-257.
50. Young RM, Meyer IH: The trouble with "MSM" and "WSW": erasure of the sexual-minority person in public health discourse. Am J Public Health 2005, 95:1144-1149.

51. Harawa NT, Williams JK, Ramamurthi HC, Manago C, Avina S, Jones M: Sexual behavior, sexual identity, and substance abuse among lowincome bisexual and non-gay-identifying African American men who have sex with men. Arch Sex Behav 2008, 37:748-762.

\section{Pre-publication history}

The pre-publication history for this paper can be accessed here: http://www.biomedcentral.com/1471-2458/11/20/prepub

doi:10.1186/1471-2458-11-20

Cite this article as: Marshall et al:: Pathways to HIV risk and vulnerability among lesbian, gay, bisexual, and transgendered methamphetamine users: a multi-cohort gender-based analysis. BMC Public Health 2011 11:20.

\section{Submit your next manuscript to BioMed Central and take full advantage of:}

- Convenient online submission

- Thorough peer review

- No space constraints or color figure charges

- Immediate publication on acceptance

- Inclusion in PubMed, CAS, Scopus and Google Scholar

- Research which is freely available for redistribution 